\title{
Assessment of Service Desk Quality at an Academic Health Sciences Library
}

\author{
Amy E. Blevins \\ Jen DeBerg \\ Elizabeth Kiscaden
}

\begin{abstract}
Due to an identified need for formal assessment, a small team of librarians designed and administered a survey to gauge the quality of customer service at their academic health sciences library. Though results did not drive major changes to services, several important improvements were implemented and a process was established to serve as a foundation for future use. This paper details the assessment process used, as well as lessons learned during the project.
\end{abstract}

KEYWORDS. Academic health sciences libraries, assessment, quality of service, service desks

\section{Author information}

Amy E. Blevins, MALS (aeblevin@iu.edu) is Associate Director for Public Services, Ruth Lilly Medical Library, Indiana University School of Medicine, 975 W. Walnut Street, IB 100, Indianapolis, IN 46202. She was formerly one of the Clinical Education Librarians at Hardin Library for the Health Sciences in Iowa City, IA.

Jennifer DeBerg, OT, MLS (jennifer-deberg@uiowa.edu) is Clinical Education Librarian, Hardin Library for the Health Sciences, University of Iowa, 600 Newton Road, Iowa City, IA 52245.

Elizabeth Kiscaden, MLIS, AHIP (elizabeth-kiscaden@uiowa.edu) is Head, Hardin Library Services, University of Iowa, 600 Newton Road, Iowa City, IA 52242-1098.

This is the author's manuscript of the article published in final edited form as: 


\section{INTRODUCTION}

In an era when libraries are facing shrinking budgets and unprecedented competition from online search engines, it is essential that libraries provide the best possible service to their users. Library staff working service desks are often the first point of contact for library users, whether that contact is in-person, chat, phone, or e-mail transactions. In recent years, many libraries have transitioned to single point-of-service desks rather than the separate reference and circulation desks of the past. This was a significant change to libraries' service model, but the challenge was embraced with the goal of providing more seamless and higher quality service for library users. ${ }^{1,}$ 4,5

Library metrics are collected by libraries of all types and reported out to individual institutions, consortia, and organizations such as the Association of Research Libraries (ARL) and the Association of Academic Health Sciences Libraries (AAHSL). Health sciences libraries are commonly measured by AAHSL using criteria including collection size, number of subscription databases, total full-time equivalent (FTE) staff, and expenditures. While libraries are careful to capture these metrics annually, evaluating customer service is conducted rarely, if at all.

A recent literature search revealed a lack of articles discussing the evaluation of customer service in health sciences libraries. Additionally, the Medlib-L listserv for medical librarians was used to ask other librarians about their experiences with service quality assessment. There were no responses from librarians that had undertaken a customer service evaluation. 
Recognizing that customer service is a core component of library services and that others may have similar needs, this article shares the experiences of an academic health sciences library with creating a tool and using it to measure the quality of customer service at library service desks in an academic health sciences library.

\section{BACKGROUND}

Several tools are available for measuring customer service in libraries, the two primary tools being SERVQUAL and LibQUAL+. SERVQUAL (SERVice QUALity) is a 22-question instrument that asks questions across five dimensions: reliability, assurance, empathy, responsiveness, and tangibles. ${ }^{2}$ Similarly, LibQUAL+, modified from SERVQUAL, is a $22-$ question instrument that asks questions across three dimensions: Affect of Service, Information Control, and Library as Place. ${ }^{6}$

The cost of administering LibQUAL+ is a barrier for use at many institutions. At the time of this publication, the cost of administering LibQUAL + starts at $\$ 3,200$. While SERVQUAL is freely available, a criticism of the tool is the length and redundancy of the instrument. ${ }^{3}$ While both of these tools are promoted as customer service instruments, the scope of these instruments are broad, measuring items such as functionality of equipment, physical facilities, and availability of resources.

Hardin Library for the Health Sciences is a part of the University of Iowa Libraries system and serves the information and research needs of the University of Iowa Health Sciences Colleges and the University of Iowa Hospitals \& Clinics. Hardin Library employs 10 librarians, 6.5 FTE library assistants, and approximately 5.5 FTE student workers. The library has two 
service desks: one is a combined reference and circulation desk at the main entrance on the third floor, and the second is a smaller circulation desk at the first-floor entrance. At the time of the survey, the library had an additional service desk on the second floor of the building. This desk resided on a floor with no entrance/exit to the building. At one time, that area was used to house simulators and anatomical models. Due to low traffic in that area of the building, the desk is no longer staffed and the items have been moved to a more secure location. The combined desk on the third floor is staffed by librarians, library assistants, and student workers, while the desks on the first and second floors have been staffed solely by student workers. In recent years, the library switched from having two people staff the desks to having a single person at the desk since the number of questions asked is much lower than in the past. The person working at the main desk is responsible for monitoring the library's chat, e-mail, phone, and in-person questions. The other desks only handle in-person requests.

All new employees, including librarians, library assistants, and student workers, are given minimal training in customer service transactions. This training includes telephone procedures, responding to chat and e-mail transactions, and basic dress code guidelines. Additionally, student workers are given a module on communication and customer service as a part of their online training series. Before investigating restructuring customer service training, it was important to assess the level of customer service library users received at the service desks using a tool that focused on potential areas of concern for the library staff. In addition, this tool was designed to measure library user perceptions and satisfaction. This library has a reference assistant who checks the accuracy and quality of graduate student worker interactions. Undergraduate student workers are trained to refer any questions they cannot answer to the main service desk. 


\section{METHODOLOGY}

In order to conduct an internal assessment to determine how library users on- and off-campus perceived the quality of customer service at this library's service desks, a tool was sought that was freely available and short enough that library users could complete quickly. Three librarians reviewed the existing literature for similar surveys and developed a set of questions to assess customer service quality. They sought feedback from other library staff members before being finalized. In addition, a discussion with staff at the Human Subjects Research Determination office led to referral of their handbook (http://hso.research.uiowa.edu/human-subjects-researchdetermination-booklet-0), which stated that this type of survey did not qualify as human subjects research since it is a service survey.

The survey tool was released in print and as an online survey. Both were available for four weeks during February 2015. The print version was placed at each of the service desks along with discreet boxes where the completed versions could be returned. Qualtrics was used to create an online version of the assessment tool. The link to the survey was included on all emails from the service desks, posted to the library's home page, and sent out via the library's Facebook and Twitter feeds. Library liaisons were encouraged to include a link to the survey in their e-mail signatures as well as sending out a standard e-mail to all of their departments.

The tool included five questions on library service plus demographic information. Users were asked to provide feedback on multiple aspects of the following:

- "Customer service you have experience in-person at our service desks."

- "Customer service you have experiences at our service desks via phone, chat, or e-mail." 
- "Overall quality of service experiences at our service desks (in-person, or via phone, chat, or e-mail)."

- "What can we do to improve your experience at our service desks?"

- "What is something you think we do well at our service desks?"

- "What type of library user are you?"

- "What college are you enrolled in?"

The full survey can be seen in the Appendix.

\section{RESULTS}

Of the 122 respondents, 48 were faculty or staff, and 52 were graduate/professional students. Only 3 were emeritus/retired staff, 7 were undergraduate students, 1 was a fellow, and 11 were University of Iowa Hospitals and Clinics faculty or staff. No residents or unaffiliated users responded to this survey. Most of the respondents were from the College of Nursing (33), followed by the College of Medicine (15), College of Liberal Arts and Sciences (1), Graduate College (1), and College of Education (1) (See Figure 1).

\section{[INSERT FIGURE 1 HERE]}

\section{Legend: FIGURE 1. Number of Respondents from University of Iowa Colleges}

During the weeks that the survey remained open, 122 responses were submitted via Qualtrics. No paper responses were received. Overall, results of the survey were positive, with a 
mean score of 4.5 out of 5.0 on a modified Likert scale (see Tables 1, 2, and 3. which were created using Qualtrics).

[INSERT TABLE 1 HERE]

Legend: TABLE 1. Customer Services You Have Experienced In-person at the Service Desks

[INSERT TABLE 2 HERE]

Legend: TABLE 2. Customer Service You Have Experienced at Service Desks via Phone, Chat, or E-mail

[INSERT TABLE 3 HERE]

Legend: TABLE 3. Overall Quality of Service Experienced at Service Desks (In-person or via Phone, Chat, or E-mail

Text comments provided library staff with positive reinforcement for what was being done well at this library's service desks. Examples of some of the positive comments received include: "You all do a great job," "This is the best service I can imagine already," "Made me feel like my problem was important to staff," "Very quick to respond and responses have been helpful," and "You always ensure my needs are met."

Several other comments identified some areas that needed improvement. One of these areas was ensuring follow-up when an e-mail question was forwarded by desk staff to another librarian. There were several comments on this subject, including "the person I e-mailed had to 
refer my problem to a higher level and I don't know what happened next." Another area for improvement that surfaced from the evaluation was the need for staff nametags to better identify the role of the employee, be that a librarian or a student worker. As one respondent commented, “More clearly state one's role, healthcare librarian, work-study student; helps me word my question (level of technical language to use, etc.)."

\section{DISCUSSION}

Results of the assessment were shared with staff and are being utilized to improve training and to revise policies. As a result of this assessment, all new student worker nametags now identify the employee as a student worker, to better indicate their role. Additionally, the reference desk team discussed and implemented some strategies for closing the loop on e-mail communication, primarily by copying oneself on the message and following up to ensure that the question had been answered. This prevented the librarian from having to check the reference e-mail account when they were no longer staffing the desk.

As a follow-up to this assessment, a document outlining best practices was developed. The best practices include a reminder to wear identification, identify oneself when answering the phone or chat, closing the loop with e-mail communication, and reminders regarding professional behavior at the desk. This document was added to the internal reference desk home page as a reminder to students and staff that cover reference services.

There were numerous lessons learned while working on this project. The first was that library staff expectations and standards for service seem to be higher than that of the people being served. Because library staff appreciate the importance of providing the highest level of 
service, they were willing to make changes to improve services even though the results of the survey were positive and overall unsurprising. In addition, by talking with library staff about this project and working together to develop the questions for this tool, the librarians and paraprofessional staff had the opportunity to bond over shared philosophies and goals for the library as a whole. The project ended up being more enjoyable and easy than initially anticipated.

Since this project focused on satisfaction and library user perceptions, future areas of study might include comparing the responses of full-time library staff to those of graduate and undergraduate student workers. A tool is currently under development to assess response time and response quality for e-mail reference questions. In addition, it would be interesting to look at the amount and difficulty of questions coming through the service desk now as compared to five or ten years ago.

\section{CONCLUSION}

Ultimately, this assessment provides a benchmark of the quality of customer service at this library's service desks. The staff were pleased by the positive responses received on this assessment, indicating that the current level of customer service is already high. In order to measure changes in service quality and continue to develop methods for ongoing improvement, the assessment will be conducted periodically every three to five years. The number of questions asked through library service desks has decreased, but the obligation to provide the highest level of service has not. As library budgets are constantly threatened, it is of the utmost importance that every person that interacts with the library, be it in person or otherwise, has a wonderful experience. This dedication to quality service is not unique to the University of Iowa. Other 
librarians may find this tool to be a free and useful way to evaluate the quality of service provided by their staff. It is also important to remember that even if the service levels are already high, there is almost always room for improvement.

Received: March 16, 2016

Revised: April 11, 2016

Accepted:

\section{REFERENCES}

1. Bradigan, Pamela S., and Ruey L. Rodman. "Single Service Point: It's All in the Design." Med Ref Serv Q 27, no. 4 (Winter 2008): 367-378. doi: 10.1080/02763860802367755.

2. Jones, Phillip J., and Tim Zou.“The Process and Promise of Consolidating Public Service Desks: You Can't Hurry Love.” Brick and Click Libraries: Proceedings of an Academic Library Symposium, Maryville, MO. November 6, 2009. Accessed on April 27, 2016 from http://eric.ed.gov/?id=ED507380

3. Hunter, Diane, and Mary E. Anderson. " 2 for the Price of 1: Combining Access Services and Reference Desks." Brick and Click Libraries: Proceedings of an Academic Library Symposium, Maryville, MO. November 4, 2011. Accessed on April 27, 2016 from

http://eric.ed.gov/?id=ED526899

4. Cook, Colleen, and Bruce Thompson. "Reliability and Validity of SERVQUAL Scores Used to Evaluate Perceptions of Library Service Quality.” Journal of Academic Librarianship 26, no. 4 (2000): 248-258. 
5. Thompson, Bruce, Martha Kyrillidou, and Colleen Cook. 'Library Users' Service Desires: A LIBQUAL+ STUDY.” Library Quarterly 78, no. 1 (January 2008): 1-18.

6. Crossno, Jon E., Brenda Berkins, Nancy Gotcher, Judith L. Hill, Michelle McConoughey, and Mitchel Walters. "Assessment of Customer Service in Academic Health Care Libraries (ACSAHL): An Instrument for Measuring Customer Service.” Bulletin of the Medical Library Association 89, no. 2 (April 2001): 170-176. 